Vol. 68, N. ${ }^{\circ}$ Io8 (noviembre 20I6), 35-58

\title{
VÍNCULOS MONETARIOS Y FISCALES CON LAS POLÍTICAS DE ESTABILIZACIÓN
}

\author{
GRACE LLERENA
}

Flacso-Ecuador

Recepción manuscrito: 23 de septiembre de 2016
Aceptación versión final: 31 de octubre de 2016

RESUMEN El paradigma que ha reflexionado más ampliamente sobre una economía intrínsecamente monetaria es el poskeynesiano. J. M. Keynes (1933) plantea que las fluctuaciones de la demanda efectiva corresponden a un fenómeno monetario. Al analizar la inversión bajo esta propuesta, como un canal que afecta a la demanda agregada, se considera, de forma casi exclusiva, la creación endógena de dinero por parte de los bancos como la única fuente posible de financiamiento de la firma. Se ha relegado el planteamiento de Keynes respecto a la teoría de la preferencia por liquidez como otra fuente de financiamiento que coexiste con la creación endógena de dinero. Este documento propone que la reincorporación de la preferencia por liquidez al análisis del financiamiento de las inversiones puede contribuir a identificar los vínculos monetarios y fiscales con las políticas de estabilización, más aún en países que no cuentan con moneda propia.

PALABRAS ClaVE Dinero endógeno, preferencia por liquidez, política monetaria poskeynesiana, política fiscal, financiamiento de las inversiones de las firmas.

ABSTRACT The paradigm that has more extensively reflected on an intrinsically monetary economy is the Post-Keynesian. J. M. Keynes (1933) considers that fluctuations in the effective demand correspond to a monetary phenomenon. Upon analyzing investment under this proposal, as a channel that affects the aggregate demand, the endogenous creation of money by banks is almost exclusively considered as the only possible source of financing for a firm. Keynes' thesis respect of the liquidity preference theory as another source of financing that coexists with the endogenous creation of money has been pushed into the background. This paper claims that the return of the liquidity preference to the investment financing analysis can help to identify the monetary and fiscal links with the stabilization policies, even more in countries which do not own their own currencies.

KEYWORDS Endogenous money, liquidity preference, Post-Keynesian monetary policy, fiscal policy, financing of investment for firms.

JEL CODE E12.

\section{INTRODUCCIÓN}

Ecuador, uno de los tres países dolarizados en América con la moneda de los Estados Unidos, tras dieciséis años de adoptado este esquema monetario, atraviesa un particular momento 
histórico. Ha sufrido importantes shocks externos, tales como: la caída del precio del petróleo desde el segundo semestre de 2014, la apreciación del dólar y el encarecimiento del financiamiento externo, lo cual se ha visto reflejado en una desaceleración de su desempeño económico. En este documento se analiza particularmente el período comprendido entre el primer trimestre de 2014 y el segundo trimestre de 2016 con información del Banco Central del Ecuador. En el segundo trimestre de 2014 se registra el mayor precio por barril de petróleo del período de análisis (USD 105,79 en junio); este hecho está correlacionado directamente con el desempeño económico del país, ya que en ese mismo trimestre se presenta la mayor tasa de crecimiento del producto interno bruto ([PIB] 2,61\%) del período. A partir del tercer trimestre de 2014, el precio del barril de petróleo comienza a caer aceleradamente hasta llegar al precio más bajo en el primer trimestre de 2016 (USD 30,32 en febrero), lo cual ha marcado importantes límites en el desempeño de la economía ecuatoriana.

En cinco de los diez trimestres analizados la tasa de crecimiento económico es negativa y en el segundo trimestre de 2015 presenta un crecimiento marginal (o,17\%). En el primer trimestre de 2016 se presenta el peor desempeño económico del periodo de análisis $(-2,87 \%)$. De igual forma, el índice de términos de intercambio ${ }^{1}$ decreció en este período, pasando de 124,91 en el primer trimestre de 2014 a 79,26 en el segundo trimestre de 2016. Los shocks exógenos en la economía ecuatoriana también han generado importantes efectos internos. En cuanto a los hogares, en el primer trimestre de 2014, su consumo presentó una tasa de crecimiento trimestral positiva pero marginal de $0,003 \%$, en tanto que para el segundo trimestre de 2016 la tasa de crecimiento trimestral es negativa y alcanza 1,21\%. Este hecho también se refleja en la demanda interna, que registró una tasa de crecimiento trimestral positiva de $2,25 \%$ en el primer trimestre de 2014 y negativa de 0,71\% en el segundo trimestre de 2016.

De igual forma, los hogares presentan una mayor propensión a ahorrar. Se puede notar que en el primer trimestre de 2016, trimestre de peor desempeño de la economía ecuatoriana del período de análisis, se registra la segunda mayor tasa de crecimiento trimestral de los depósitos con $28,3 \%$, la cual es únicamente superada en el cuarto trimestre de 2015, cuando registra el 34,3\%. Más aún, desde el cuarto trimestre de 2015 al segundo trimestre de 2016, se registra una recomposición de los depósitos de los hogares. El volumen de depósitos de 30 a 60 días aumentó. Se resalta particularmente el primer trimestre de 2016, debido a que en este trimestre los depósitos de 30 a 60 días crecieron $59,1 \%$. Lo anterior muestra que cuando los hogares ecuatorianos reciben malas noticias respecto al desempeño económico, aumentan su preferencia por mantener depósitos de disponibilidad inmediata ante cualquier eventualidad, es decir, aumentan su preferencia por liquidez.

En cuanto a las firmas se presenta una desaceleración de sus inversiones en el período de análisis. En el 2014, la formación bruta de capital fijo (FBKF) del sector privado presentó una tasa de crecimiento anual de $15 \%$, no obstante, para el año 2015 la tasa de crecimiento se reduce 4 puntos porcentuales y alcanza el 11\%. La inversión total en la economía también se reduce, pasando de una tasa de crecimiento trimestral de $7,85 \%$ en el primer trimestre de 2014 a -0,96\% en el segundo trimestre de 2016. Debido a que el consumo se deprimió, las firmas, en respuesta a la reducción de sus ventas, han disminuido sus inversiones y han despedido trabajadores. 
Los bancos privados presentan una mayor preferencia por liquidez. Comparando el primer trimestre de 2014 y el segundo trimestre de 2016, los bancos comerciales redujeron su colocación de crédito en USD 130,8 millones. La tasa de crecimiento trimestral del volumen de crédito en este último trimestre es negativa y alcanza el o,49\%. No obstante, se puede notar, por ejemplo, que en febrero y marzo de 2016 aumentó la demanda de crédito en 20,24\% y 13,62\%, respectivamente; y, en abril decreció en 9,09\%, manteniéndose así hasta finalizar el segundo trimestre de este año, lo cual también puede reflejar una reducción de la actividad económica y/o la decisión de esperar de hogares y firmas para financiar sus gastos de consumo e inversión.

Por otro lado, el gobierno depende principalmente del ingreso percibido por las rentas petroleras y la recaudación tributaria para financiar su presupuesto, ya que no cuenta con un seguro petrolero ni con un fondo de estabilización. En el período comprendido entre el primer trimestre de 2014 y segundo trimestre de 2016, su ingreso total se redujo en USD 2040,05 millones. Se presenta un importante déficit público y un problema de liquidez para solventar sus compromisos, particularmente la compra de bienes y servicios y el pago de deuda que al momento están siendo cubiertos de forma emergente con un creciente déficit público externo. En enero de 2014, la deuda externa pública total como porcentaje de PIB se situaba en el 12,7\%, en tanto que para junio de 2016 alcanzó el 23,5\%.

Ante esta coyuntura, el propio Estado comienza a reducir su gasto, tanto corriente — con el consecuente despido de funcionarios públicos y su efecto en la reducción del consumo- como de inversión. En el período de análisis, el gasto total del gobierno se redujo en USD 1178,54 millones. El gasto en sueldos se redujo en USD 276,02 millones. De igual forma, la FBKF pública también se redujo. En el 2014, presentó una tasa de crecimiento anual negativa de 1\%, en tanto que para 2015, registró una tasa de crecimiento anual negativa de 19\%. Además, en cuanto el sector externo, el déficit de la Cuenta Corriente de la Balanza de Pagos es persistente en siete de los diez trimestres analizados — USD 1848,45 millones-, lo cual se explica tanto por el saldo negativo de la Balanza de Bienes en cinco de los diez trimestres analizados, registrando un valor de USD 850,26 millones. Las exportaciones sumaron USD 53.891,91 millones y las importaciones USD 54.742,16 millones, en el periodo analizado. El déficit de la Balanza de Servicios y Renta ha sido persistente en los diez trimestres analizados y asciende a USD 6532,44 millones. Lo cual marca límites importantes en cuento al ingreso de dólares al circuito monetario.

La economía ecuatoriana se encuentra en una etapa de contracción del ciclo económico que podría traer como consecuencias un mayor nivel de desempleo y también inestabilidad financiera. En este contexto, los hacedores de política económica indican que están «atados de manos» debido a que están imposibilitados de aplicar políticas contracíclicas que incentiven y reduzcan los efectos negativos sobre la demanda agregada, debido a que no cuentan con la política monetaria como un instrumento activo, por lo cual, justifican, así, la aplicación de políticas procíclicas, tales como la reducción del gasto público y/o el incremento de los impuestos.

El objetivo de este trabajo es, entonces, identificar los vínculos monetarios y fiscales existentes con las políticas de estabilización desde el marco teórico poskeynesiano, en un régimen de dolarización. Esta área no se ha investigado con mayor profundidad teórica —menos aún para países dolarizados- más allá de las reflexiones empíricas realizadas por los hacedores de 
política pública o de ciertos investigadores. Se entenderá como políticas de estabilización en este documento a las políticas monetaria y fiscal activas que permitan suavizar el ciclo del PIB. ${ }^{2}$

Para cumplir con el objetivo planteado, en la segunda sección se abordarán con mayor profundidad las derivaciones teóricas de la endogeneidad del dinero de la nueva síntesis neoclásica (NSN, en adelante) y la poskeynesiana, y se presentarán sus diferencias en los ámbitos de marco teórico que rige la acción de los bancos centrales, la determinación de las herramientas de política monetaria y las funciones del dinero. La tercera parte muestra cómo la teoría poskeynesiana es una herramienta útil para comprender la existencia de vínculos monetarios y financieros con las políticas de estabilización. No obstante, la consistencia de este paradigma aún es incompleto, por lo cual, se reflexiona sobre las modalidades de financiamiento de las inversiones como un canal que afecta la demanda agregada. Además, se analiza la importancia de la teoría de la preferencia por liquidez presentada por J. M. Keynes (1936) para identificar si existe una relación entre la preferencia por liquidez y el ciclo económico. En la última sección del documento se presentan las conclusiones.

\section{POLÍTICA MONETARIA: NATURALEZA DEL DINERO, CARACTERÍSTICAS DE LA OFERTA MONETARIA Y CICLO ECONÓMICO}

\section{VARIABLES MONETARIAS Y SECTOR REAL DE LA ECONOMÍA}

A lo largo de la historia, las diferentes escuelas de pensamiento económico han buscado describir su concepción del mundo y el papel que juega la moneda. El modelo representativo de economía de la síntesis neoclásica y la NSN —o neokeynesianismo- se representa con la secuencia: Commodity - Money - Commodity $\left(C-M-C^{\prime}\right)$, donde - $C$ - representa el consumo de mercancías; - $M$-, dinero; y - $C$-', consumo de mercancías. En efecto, en esta concepción, las actividades económicas comienzan cuando los ingresos disponibles por la realización del trabajo son asignados una parte al consumo (-C-) y la parte restante al ahorro (-S-). Ese ahorro es depositado en los bancos comerciales que, al ser meros intermediarios financieros, lo destinan a financiar la inversión de las firmas $(-M-)$, por lo cual otros hogares y firmas pueden consumir (-C'-). En este marco analítico, el dinero que detentan los agentes económicos sirve solo para facilitar el intercambio, la moneda cumple exclusivamente la función de medio de cambio.

Por el contrario, los poskeynesianos y de igual forma los neomarxistas presentan un modelo representativo de la economía con una secuencia: Money-Commodity-Money $\left(M-C-M^{\prime}\right)$, donde $-M$ - representa dinero, $-C$ - consumo de mercancías y - $M$ '- dinero más ganancia o acumulación de capital. Las actividades económicas comienzan por la creación de un depósito monetario por parte de los bancos comerciales para que las firmas puedan financiar sus inversiones $(M)$, con dichos depósitos los empresarios demandan la producción de los bienes que requieren $(-C-)$. Las actividades económicas se desarrollan en un marco de incertidumbre por el futuro, por lo cual, los agentes económicos presentan preferencia por liquidez como un mecanismo de reserva de valor. La moneda cumple con las funciones de medio de cambio, pero también con la de reserva de valor. El debate - desde estas dos visiones del mundo económico (ver Tablas 1, 2 y 3) - sobre la naturaleza del dinero busca responder si las variables 
monetarias afectan al sector real de la economía, ${ }^{3}$ no solo en el corto plazo, como ya era ampliamente aceptado, sino también en el largo plazo, lo cual es fundamental para analizar si la política monetaria puede ayudar o no a suavizar las fluctuaciones del ciclo económico.

[L]as relaciones dinámicas entre el dinero, la inflación y la producción reflejan tanto la forma en que los agentes privados responden a las perturbaciones económicas y la forma en que la autoridad de política monetaria responde a las mismas perturbaciones. Por esta razón, las correlaciones de corto plazo tienden a variar entre los distintos países, ya que diferentes bancos centrales implementan políticas de diferentes maneras, las cuales cambian en el tiempo en un solo país, tal como varían las fuentes de perturbaciones económicas. (Walsh, 2010, p. 29)

En un primer momento, el debate se situó en la naturaleza exógena versus endógena del dinero. Desde el enfoque de síntesis neoclásica se plantea que el dinero es exógeno y no afecta a las variables reales en el largo plazo. La herramienta fundamental de política monetaria que aplica el banco central es el control de la cantidad de dinero que circula en la economía. Por otro lado, para los poskeynesianos el dinero es endógeno y afecta a las variables reales en el largo plazo. La principal herramienta de política monetaria del banco central es la determinación de la tasa de interés. Un segundo momento, el cual analizaremos en este documento, inicia cuando uno de los más importantes representantes del paradigma neokeynesiano o de la NSN, Woodford (2003), plantea que el dinero es endógeno. Se acepta, así, la naturaleza endógena del dinero y se presenta un punto de convergencia con la visión poskeynesiana; de esta manera se contrastan dos tipos de endogeneidad del dinero. No obstante, los mecanismos subyacentes para explicar la dinámica entre el sector monetario y real de la economía son diferentes; además, la principal herramienta de política monetaria de la NSN es fijar la tasa de interés real siguiendo la regla de Taylor. Como lo expresó Lucas (1996) en su discurso del Premio Nobel, «La tensión entre dos ideas incompatibles ha estado en el centro del debate de la teoría monetaria: los cambios en el dinero son cambios en unidades neutrales y, los cambios en el dinero inducen movimientos en el empleo y la producción en la misma dirección».

\section{¿POR QUÉ ES IMPORTANTE ABORDAR CON PROFUNDIDAD}

EL DEBATE SOBRE LA ENDOGENEIDAD DEL DINERO?

La convergencia en el debate respecto a la naturaleza endógena del dinero desde la NSN así como de los poskeynesianos, marca un nuevo momento en la teoría monetaria que requiere mayor profundidad en el análisis de las derivaciones teóricas inherentes. En primer lugar, la endogeneidad del dinero presentado por estas dos escuelas conlleva a que la oferta monetaria sea caracterizada como endógena y horizontal y que, por tanto, se reflexione sobre cuáles son y cómo deben aplicarse las herramientas de política monetaria por el banco central. Esta reflexión se circunscribe en el rol que toma la moneda en los modelos económicos representativos tanto de la NSN ( $\left.C-M-C^{\prime}\right)$, así como de los poskeynesianos $\left(M-C-M^{\prime}\right)$. Las dos escuelas presentan un mismo punto de partida, en el marco institucional y monetario actual. Los bancos centrales han abandonado el control de la cantidad de dinero que circula en la economía como variable objetivo de la política monetaria, particularmente por el reconocimiento explícito de que no es posible controlar la oferta monetaria. Por lo tanto, la herramienta de gestión 
del banco central es la determinación de la tasa de interés. Es así que la primera implicación fundamental del análisis de la endogeneidad del dinero se encuentra en la determinación de las herramientas de política monetaria que, en efecto, para estas dos escuelas, es la misma. No obstante, los fundamentos teóricos que guían su determinación así como sus mecanismos subyacentes son diferentes (Dullien, 2011).

Como argumenta Fontana y Setterfield (2009), los poskeynesianos y la NSN creen que las tasas de interés reales más altas desaceleran la economía. Los poskeynesianos argumentan que esto se debe a que las altas tasas de interés tienden a desincentivar la inversión, generando así un impacto negativo en la distribución del ingreso. En contraste, la NsN explica que las altas tasas de interés aseguran un mayor ingreso futuro reduciendo el ahorro presente, disminuyendo, así, la necesidad de trabajar ahora para adquirir activos, por lo que la reducción de la oferta de trabajo conduce a una reducción de la producción corriente. Esto permite analizar una segunda implicación que puede expresarse de forma equivalente. A pesar de que estos dos paradigmas compartan la visión sobre la naturaleza endógena del dinero, difieren en las funciones que le asignan debido al rol que toma el dinero en sus modelos representativos.

En el modelo de la NSN, el dinero es un medio de intercambio, pero no una reserva de valor. Sin embargo, se estaría tentado a afirmar que en este paradigma el dinero también es reserva de valor, ya que las funciones de utilidad que se utilizan en los modelos money-in-the-utility consideran los real balances ( $\mathrm{Mt} / \mathrm{Pt}$ ), lo cual podría llevar a pensar que la moneda sea considerada reserva de valor. Sin embargo, Romer (2011, pp. 239-240) argumenta que «Feenstra (1986) demuestra formalmente que este dinero en la función de utilidad [money-in-the-utility] y los beneficios de transacciones de las tenencias de dinero son observacionalmente equivalentes». De igual forma, explica que «el supuesto de que el dinero es una fuente directa de utilidad es un atajo. En realidad, los individuos guardan efectivo no porque les provee utilidad directamente, sino porque les permite comprar bienes más fácilmente. Se puede pensar en la contribución de $(M t / P t)$ a la función objetivo como reflejo de esta mayor ventaja en lugar de utilidad directa».

Se desprende de esto que el dinero, a pesar de ser endógeno en la NSN es exclusivamente medio de cambio, no reserva de valor, lo cual implica omitir el punto central de la Teoría general del empleo, el interés y el dinero de J. M. Keynes (1936), la llamada «revolución keynesiana», centrada en la idea de dinero como reserva de valor. En efecto, para los poskeynesianos el dinero también es endógeno, no obstante, no solo cumple con la función de medio de cambio, sino también el de reserva de valor. Se presenta un juicio común respecto a la pregunta ¿cómo se crea el dinero?, pero hay una diferencia muy importante en la respuesta de ¿para qué sirve el dinero?; es decir, respecto a las funciones del dinero. Esta diferencia nos lleva a la tercera implicación, el análisis del marco teórico que guía la acción del banco central. Galí (2008) y Woodford (2003) plantean que la categoría central de análisis de la NSN es la tasa natural de interés. Todo el análisis de este paradigma se basa en el supuesto de existencia de esta categoría wickseliana. Esto nos lleva a preguntarnos ¿cuál es la dinámica de la política monetaria que plantea este paradigma? Para responder a esta pregunta, nos situaremos en el análisis de la teoría de fondos prestables desarrollada por Wicksell (1898) (ver Figura 1). 
Tabla 1. Matriz de balance

\begin{tabular}{lcccc}
\hline & HOGARES & FIRMAS & BANCOS COMERCIALES & $\Sigma$ \\
\hline Capital físico & & $p K$ & $-\mathrm{M}$ & $p K$ \\
\hline Depósitos & $\mathrm{M}$ & & & 0 \\
\hline Bonos & $p_{B} B$ & $-p_{B} B$ & $-\mathrm{L}$ & 0 \\
\hline Crédito & & $\mathrm{L}$ & 0 & 0 \\
\hline Balance & $-\mathrm{V}_{\mathrm{H}}$ & $-\mathrm{V}_{\mathrm{F}}$ & 0 & $-p K$ \\
\hline$\sum$ & 0 & 0 & 0 & 0 \\
\hline
\end{tabular}

Fuente: Lavoie, 2014, p. 187. Nota: Se denomina mainstream a la síntesis neoclásica, a pesar que los tres últimos puntos del debate aún lo mantiene la NSN.

Tabla 2. Matriz de Transacciones para el periodo $t$

\begin{tabular}{|c|c|c|c|c|c|c|c|}
\hline & & \multirow[t]{2}{*}{ HOGARES } & \multicolumn{2}{|c|}{ FIRMAS } & \multicolumn{2}{|c|}{ BANCOS COMERCIALES } & \multirow[t]{2}{*}{$\Sigma$} \\
\hline & & & CORRIENTE & CAPITAL & CORRIENTE & CAPITAL & \\
\hline Consumo & & $-p C$ & $p C$ & & & & 0 \\
\hline Inversión & & & $\mathrm{pl}$ & $-\mathrm{pl}$ & & & 0 \\
\hline Salarios & & $\mathrm{wN}$ & $-\mathrm{wN}$ & & & & 0 \\
\hline Beneficios de las firmas & & & $-\pi$ & $\pi$ & & & 0 \\
\hline Beneficios de los bancos & & $\mathrm{i}_{\mathrm{L}} \mathrm{L}$ & & & $-\mathrm{i}_{\mathrm{L}} \mathrm{L}$ & & 0 \\
\hline \multirow[t]{2}{*}{ Intereses } & Bonos & $\mathrm{B}$ & $-B$ & & & & 0 \\
\hline & Créditos & & $-\mathrm{i}_{\mathrm{L}} \mathrm{L}$ & & $\mathrm{i}_{\mathrm{L}} \mathrm{L}$ & & 0 \\
\hline \multirow[t]{3}{*}{ Stocks $(\Delta)$} & Depósitos & $-\Delta \mathrm{M}$ & & & & $\Delta \mathrm{M}$ & 0 \\
\hline & Bonos & $-\mathrm{p}_{\mathrm{B}} \Delta \mathrm{B}$ & & $-\mathrm{p}_{\mathrm{B}} \Delta \mathrm{B}$ & & & 0 \\
\hline & Créditos & & & $\Delta \mathrm{L}$ & & $\Delta \mathrm{L}$ & 0 \\
\hline $\bar{\Sigma}$ & 0 & 0 & 0 & 0 & 0 & 0 & 0 \\
\hline
\end{tabular}

En el mercado financiero de fondos prestables, la curva de ahorro $(S)$ se deriva del comportamiento óptimo de consumo y ahorro de los hogares — condición de Euler-; y curva de inversión ( $I$ ) del producto marginal decreciente del capital. Por lo cual se analizan dos categorías centrales: las preferencias intertemporales de los hogares y la tecnología - las cuales no se modifican en el corto plazo, sino que cambian en el largo plazo, como dirían los marginalistas- son los «fundamentales». El deseo de ahorrar de los hogares y de invertir de las firmas depende básicamente de estos «fundamentales», es por eso que la tasa de interés de equilibrio que se determina en este mercado es una tasa de interés natural $(r N)$.

¿Un banco central podría conocer la tasa natural de interés? Para responder esta pregunta debemos responder previamente ¿quién conoce las preferencias de los hogares?; además de ¿quién conoce los detalles de la tecnología para calcular el producto marginal del capital? La respuesta es que no los conoce nadie, tampoco un banco central. Entonces ¿cómo puede hacer política monetaria un banco central dado que desconoce la tasa de interés natural, más aún, 
en un marco de dinero endógeno donde la herramienta de política monetaria del banco central es la determinación de la tasa de interés nominal? Para ejemplificar la respuesta se supondrá que la tasa de interés natural $(r N)$ es de $5 \%$. Además, la tasa de interés nominal (it) decidida por el banco central es de $8 \%$ y la tasa de inflación $(\pi \mathrm{t})$ corresponde a $4 \%$. La tasa de interés real se determina como la tasa de interés nominal descontada la inflación $(r t=i t$ $\pi t)$; es decir, $r t=8 \%-4 \%=4 \%$. La tasa de interés real está por debajo de la tasa natural $(r t<$ $r N)$. ¿Qué sucede en el mercado financiero de fondos prestables cuando $r t<r N$ ? Los hogares prefieren ahorrar menos de lo que las firmas quieren invertir, sin embargo, las firmas logran realizar el nivel deseado de inversión. ¿Cómo pueden las firmas invertir más de lo que los hogares están dispuestos a ahorrar? Solamente porque existe creación endógena de dinero $(b c)$ (ver Figura 2).

En efecto, cuando $r t<r N$, el gasto total de inversión de las firmas $(I)$ se financia tanto por el ahorro de los hogares $(a b)$, así como por creación endógena de dinero de los bancos privados $(b c)$. Para comprender mejor estas fuentes de financiamiento del gasto de las firmas, consideremos que los hogares fueron a trabajar en las firmas, producen mercancías y por el pago de su trabajo reciben 100 unidades monetarias. Las firmas únicamente podrían utilizar 100 unidades monetarias para invertir debido a que ése es el valor de los ingresos potenciales (ID) (IP) en la economía. Los hogares, con el dinero disponible, deben tomar sus decisiones de consumo y ahorro; deciden comprar mercancías por un valor de 70 unidades monetarias y destinar el valor restante al ahorro, 30 unidades monetarias. Ese ahorro se deposita en los bancos comerciales. Los empresarios acuden al banco a solicitar un crédito por esas 30 unidades monetarias. No obstante, las firmas invierten 50 unidades monetarias. ¿Cómo es posible que las firmas puedan invertir más que 30 unidades monetarias? Únicamente por la creación endógena de dinero de 20 unidades monetarias. Por lo tanto, la demanda agregada $(D A)$ que se compone del consumo $(C)$ e inversión $(I)$ será igual a: $D A=C+I=70+50=120$ unidades monetarias. La demanda agregada es mayor que los ingresos potenciales -100 unidades monetarias-; por lo cual, se presenta un exceso de demanda agregada $(D A>I P)$. Este exceso de demanda agregada genera inflación; no obstante, el ajuste en los precios no ocurre de forma inmediata, es paulatino; se presenta rigidez nominal debido a que no todos los días las firmas cambian los precios y los salarios nominales.

Ante este escenario, el banco central, dado que no tiene certeza del valor de la tasa de interés natural, pero observa un aumento de la inflación, concluye que la tasa de interés real está por debajo de la tasa natural. Por lo tanto, aumenta la tasa de interés nominal; esto es la regla de Taylor: un aumento en la inflación conlleva a un aumento de la tasa de interés nominal. Así, la endogeneidad del dinero de la NSN determina una regla de conducta de la política monetaria que es básicamente seguir la regla de Taylor, la cual depende fundamentalmente de la existencia de una tasa de interés natural que representa el equilibrio macroeconómico de pleno empleo donde no existe inflación. El mismo Galí (2008) en su libro Monetary policy, inflation and the business cycle indica que el edificio neokeynesiano o el de la NSN se derrumbaría sin su ladrillo fundamental: «la tasa de interés natural». Sraffa (1960) argumentó las limitaciones lógicas de la teoría de los fondos prestables de Wicksell en la controversia de los dos Cambridges en los 6o; por lo cual, los poskeynesianos no reconocen la existencia 
Tabla 3. Crédito y dinero

\begin{tabular}{|c|c|c|}
\hline CARACTERÍSTICAS & ESCUELA POST-KEYNESIANA & MAINSTREAM \\
\hline La oferta monetaria es & $\begin{array}{l}\text { Endógena y determinada por la } \\
\text { demanda }\end{array}$ & Exógena \\
\hline Dinero & $\begin{array}{l}\text { Tiene registros de contrapartida es- } \\
\text { pecialmente de los créditos generados } \\
\text { por los bancos comerciales }\end{array}$ & Cae de un helicóptero (Friedman) \\
\hline $\begin{array}{l}\text { La principal preocupación } \\
\text { es con }\end{array}$ & $\begin{array}{l}\text { Deudas ( en poder de distintos agen- } \\
\text { tes puede generar inestabilidad finan- } \\
\text { ciera) y créditos }\end{array}$ & $\begin{array}{l}\text { Activos y dinero (saldos de dinero o saldos } \\
\text { reales de la riqueza) }\end{array}$ \\
\hline El dinero está ligado a & La producción y las relaciones sociales & Intercambio privado \\
\hline Causalidad monetaria & Créditos generan depósitos & Depósitos permiten créditos \\
\hline Los Bancos son & Creadores de los flujos crediticios & Meramente intermediarios financieros \\
\hline Mecanismos de Reserva & Divisor & Multiplicador \\
\hline $\begin{array}{l}\text { El racionamiento de crédito } \\
\text { se debe a }\end{array}$ & Pérdida de confianza & Asimetría de información \\
\hline
\end{tabular}

de la tasa de interés natural y plantean que la determinación de la tasa de interés no surge de un proceso de mercado, se trata, afirman, de una variable exógena fijada por el banco central en función de sus objetivos de política monetaria — visión «horizontalista»— o del reflejo de la estructura financiera — visión «estruturalista»—, lo cual conlleva a una forma distinta de hacer política monetaria.

En efecto, en este paradigma la determinación de la tasa de interés es un objetivo intermedio, el fin es la distribución del ingreso destinado a conducir al pleno empleo y no la lucha contra la inflación. ${ }^{4}$ Aunque sí se podría seguir una regla como la de Taylor, ésta no tendría ninguna fundamentación teórica al desconocer la existencia de la tasa de interés natural, por tanto, su implementación generaría consecuencias distintas. Además, los poskeynesianos no creen que una única tasa de interés, la tasa natural, sea compatible con una situación de pleno empleo. Indican que si se adopta una política fiscal destinada a corregir la desigualdad de ingresos, el pleno empleo puede ser alcanzado con distintos niveles de tasa de interés. En este sentido, la tasa de interés debería ser fijada para asegurar transferencias de riqueza desde los individuos con mayor propensión a ahorrar hacia los de mayor propensión a consumir. En consecuencia, argumentan que los bancos centrales deberían estar más preocupados por la distribución del ingreso como motor del crecimiento económico que por un objetivo de lucha contra la inflación. ${ }^{5}$ (Piégay y Rochon, 2005, pp. 40-41). El marco teórico en el cual se circunscriba un banco central definirá los mecanismos de política monetaria que éste decida implementar y las acciones y respuesta ante los efectos subyacentes que observe en la economía, por lo cual el banco central se enfrenta a la decisión de subir o bajar las tasas de interés y a la pregunta constante de cómo afectan estos cambios a la estructura de tasas de interés y a la economía en general. 


\section{UN ENFOQUE POSKEYNESIANO A LOS VÍNCULOS MONETARIOS Y FISCALES CON LAS POLÍTICAS DE ESTABILIZACIÓN}

Después del análisis desarrollado se utilizará como marco teórico el poskeynesiano, por dos razones que se pueden resumir en: consistencia con los objetivos planteados en el presente análisis y reconocimiento de un marco conceptual aún incompleto en el cual se puede realizar contribuciones. Es consistente debido a que sin lugar a dudas es el marco teórico que da más énfasis a la economía $M-C-M^{\prime}$, que se caracteriza por ser intrínsecamente monetaria. Keynes (1933, p. 85) indica que «las fluctuaciones de la demanda efectiva pueden describirse adecuadamente como un fenómeno monetario», lo cual significa concretamente que en una economía de trueque o, de forma análoga, en una economía en la que el dinero solamente es un medio de intercambio, no podría presentarse fluctuaciones de la demanda efectiva. Por lo cual, se ha seleccionado el marco teórico poskynesiano para este análisis porque es el que más ha reflexionado sobre la naturaleza monetaria de una economía.

Es aún incompleto debido a que su modelo representativo de la macroeconomía $-A$ simple (and teachable) macroeconomic model with endogenous Money-, desarrollado por Fontana y Setterfield (2006 y 2009) en el libro Macroeconomic Theory and Macroeconomic Pedagogy, podría ser complementado con la reflexión sobre la preferencia por liquidez, lo cual proporcionará elementos esenciales para comprender las relaciones macroeconómicas que se podrían suscitar ante la determinación de la tasa de interés por parte del banco central en países que no cuentan con moneda propia, como es el caso de Ecuador. En este mismo libro, W. Carlin y D. Soskic presentaron el modelo Teaching intermediate macroeconomics using the 3-Equation Model, como una nueva herramienta pedagógica de la NSN que logra sintetizar en un nuevo marco analítico tres ecuaciones: una curva IS (Investment-Saving), una curva acelerada de Phillips y una regla de la política de tasas de interés: la regla de Taylor. El modelo busca identificar el papel que desempeñan las características estructurales de la oferta agregada y la demanda agregada y las preferencias del banco central para determinar la respuesta óptima de la tasa de interés ante shocks que podría enfrentar la economía.

Esta misma operación intelectual fue realizada por los poskeynesianos, particularmente por Fontana y Setterfield (2006 y 2009), al presentar un modelo macroeconómico con creación endógena de dinero, que considera tanto los equilibrios macroeconómicos clásicos — restricciones de oferta-, así como los keynesianos — restricciones de demanda- para analizar la actividad macroeconómica de corto plazo. En este modelo representativo de la macroeconomía poskeynesiana, ¿cómo se financian las inversiones de las firmas?: únicamente mediante la creación endógena de dinero. En este modelo y en muchos modelos poskeynesianos, ésta es la única forma de financiar las inversiones. De hecho, Fontana y Setterfield (2009, p. 146) argumentan que «las firmas [únicamente] demandan préstamos a los bancos comerciales para financiar la compra de insumos para el proceso productivo». Cabe, entonces, preguntarse cuál es el planteamiento de Keynes respecto con la forma de financiar las inversiones. Como se sabe, Keynes no criticó la teoría de fondos prestables de Wicksell, únicamente planteó una alternativa: la teoría de la preferencia por la liquidez. Para analizar mejor esta teoría, hay que reflexionar sobre el asunto mismo de la financiación de las inversiones. 
Figura 1. Mercado financiero de los fondos prestables

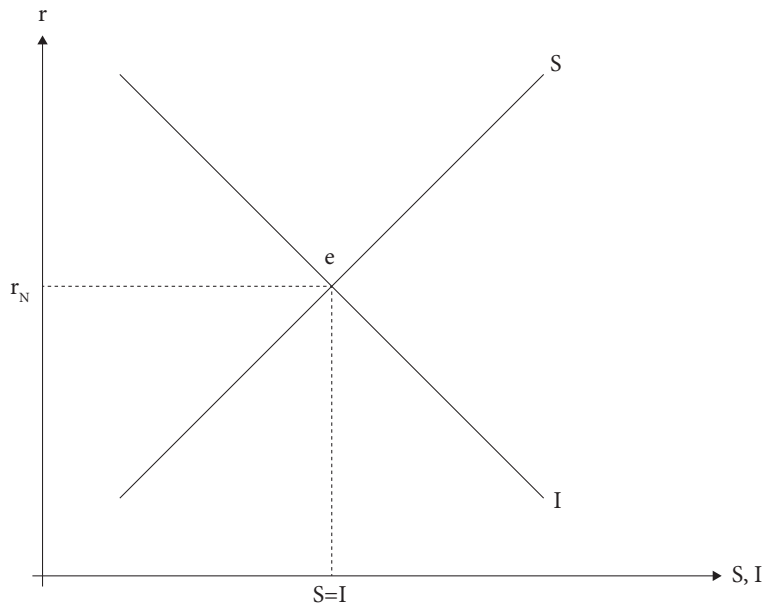

Fuente: La tasa de interés y el nivel de precios (Wicksell, 1898).

Figura 2. Mercado financiero de los fondos prestables (exceso de demanda agregada)

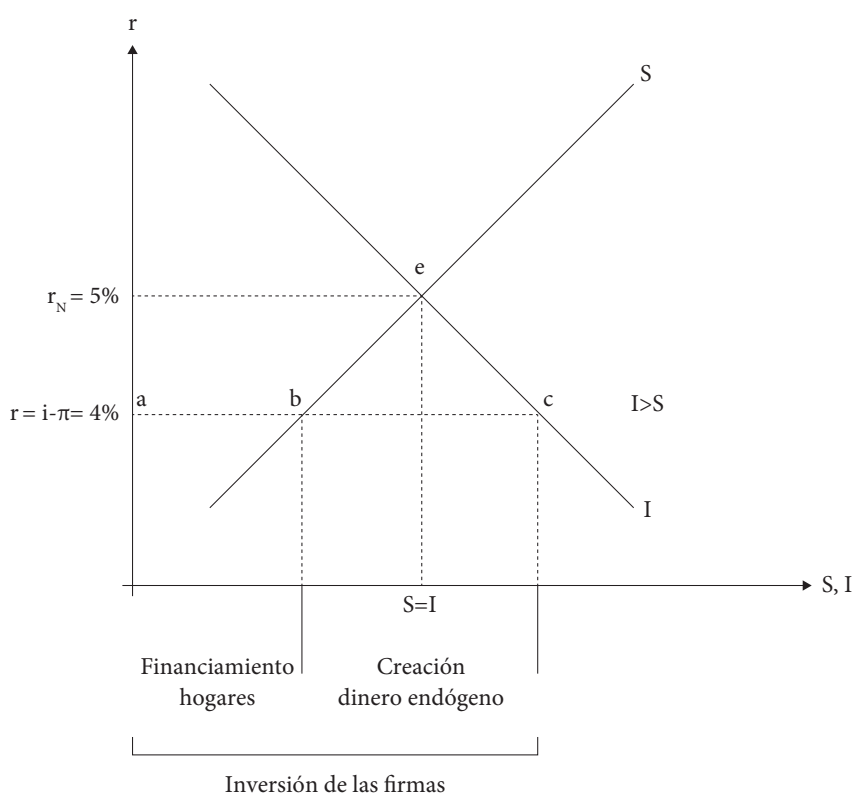

Fuente:ILa tasa de interés real es menor que la tasa de interés natural. 
Hay tres modalidades para analizar el financiamiento de las inversiones. La primera modalidad es la ley de Say. ${ }^{6}$ El modelo de economía neokeynesiano o de la NSN, $C-M-C$ ', comienza con el consumo; es decir, que si consideramos a la macroeconomía clásica, estamos situándonos en la corn economy - la economía solo trigo-. Entonces, ¿cuál es la secuencia lógica y cronológica de los eventos económicos? Primero, los trabajadores van al campo; segundo, se produce el trigo; tercero, una vez producido el trigo se paga a los trabajadores — los trabajadores pueden decidir qué porción consumir de trigo y qué porción ahorrar-; cuarto, el ahorro de los trabajadores es ofrecido al mercado financiero, se conceden préstamos a las firmas para hacer las inversiones. En esta economía las firmas financian sus inversiones con los ahoros de los hogares, por lo cual el ahorro $(S)$ genera inversión $(I)$. La causalidad macroeconómica es que el ahorro determina la inversión $(S \rightarrow I)$

La segunda modalidad es la creación endógena de dinero propuesta por los poskeynesianos radicales. La primera parte del modelo representativo de la economía poskeynesiana $(M-$ $C$ ), es analizado únicamente en términos de creación de dinero ex nihilo por los bancos comerciales; ${ }^{7}$ por lo tanto, ¿icuál es la secuencia lógica y cronológica de los eventos económicos? Primero, el empresario solicita un crédito monetario al banco debido a que cuenta con un proyecto financiable; segundo, el banco comercial crea dinero ex nihilo mediante un registro de crédito y un depósito a su favor; tercero, con ese dinero el empresario puede demandar bienes, por ejemplo, tractores — se crea la demanda; la economía inicia con dinero $(M)$-; cuarto, con el dinero que dispone, el empresario acude a los productores de tractores y solicita que se produzcan los tractores, entonces ocurre la producción de tractores; quinto, comienza la dinámica del multiplicador keynesiano: con el dinero que se pagó por los tractores, la nueva firma paga a los trabajadores que produjeron dichos tractores, los trabajadores ya cuentan con dinero. Ahora, esos trabajadores necesitan pantalones, entonces acuden a los productores de pantalones y solicitan se produzcan esos pantalones y así sucederá con todos los bienes demandados en la economía $(C)$.

El acto que permite partir al multiplicador keynesiano es la creación endógena de dinero por el banco $(M)$ y solo después se produce el consumo de tractores, pantalones, etc. $(C)$. Esta secuencia lógica es la que típicamente se encuentra en un modelo poskeynesiano; el acto inicial de inversión de las firmas es el que permite a los trabajadores ahorrar, por lo cual la inversión $(I)$ genera ahorro $(S)$. La causalidad macroeconómica es que la inversión es la que determina el ahorro $(I \rightarrow S)$. El modelo propuesto por Fontana y Setlerfield (2006 y 2009) representa esta dinámica de financiamiento de las firmas; no obstante, Keynes (1936), en la Teoría general del empleo, el interés y el dinero (TGEID en adelante), presenta una propuesta diferente: el dinero es exógeno. La segunda modalidad de financiamiento ya no sería posible; además, plantea que no es el ahorro el que determina la inversión, al contrario, es la inversión la que determina el ahorro; entonces cómo entender el planteamiento de Keynes respecto con que «el dinero es exógeno, empero, la inversión determina el ahorro» si no se categoriza ni en la primera ni en la segunda modalidad de financiamiento. Esto significa que Keynes plantea una tercera modalidad de financiamiento de la inversión de las firmas.

Para abordar el análisis de una tercera modalidad, cabría preguntarse ¿cómo se financian las inversiones de las firmas en la TGEID?, ¿ existe o no existe una forma distinta de financiamiento 
de las ya analizadas? Del análisis de la TGEID se desprende que efectivamente existe una modalidad adicional de financiamiento de las firmas que es explicada por la teoría de la preferencia por la liquidez. En efecto, podemos situar tres categorías claves para entender cómo se financian las inversiones de las firmas en la TGEID: i) la preferencia por la liquidez; ii) el dinero como reserva de valor; y iii) la incertidumbre.

Primero, previo al abordaje del enfoque poskeynesiano, es preciso recordar por qué el dinero en el modelo representativo de economía de la NSN solamente constituye un medio de cambio: los hogares mantienen riqueza en forma de activos reales - casas, terrenos, acciones, bonos, títulos, etc.-, no cuentan con dinero; el dinero es solamente un medio de cambio, no se guarda como reserva de valor; el dinero solo sirve para comprar activos reales; tan pronto los hogares cuentan con dinero inmediatamente realizan una compra y se deshacen de él, no lo acumulan, porque la reserva de valor está representada en la tenencia de casas, terrenos, acciones, bonos, títulos o en cualquier otro activo real. En la NSN, el dinero no es un activo; sin embargo, si un hogar es propietario de un terreno productivo tiene la opción de producir o alquilarlo para que otros hogares produzcan, por lo cual obtendrá renta; por mantener una acción obtendrá dividendos; por un bono recibirá intereses; entonces ¿por qué los hogares quisieran contar con dinero como un activo, como reserva de valor? Más aún, si la rentabilidad del dinero será negativa como resultado de descontar la tasa de inflación. Como lo diría Keynes: ¿Acaso los hogares están locos? Entonces, de acuerdo a esta perspectiva, solo los hogares que están locos podrían contar con dinero como reserva de valor. Del análisis de la TGEID, Keynes indica que se puede observar que los hogares cuentan con dinero como reserva de valor. Cuando los hogares ecuatorianos han pasado por momentos históricos en los que han percibido la presencia de eventos inusitados en la economía - como la crisis financiera que inició en 1998, ${ }^{8}$ una posible corrida bancaria o una contracción económica-, asustados por cualquier razón, acuden a los bancos, ${ }^{9}$ solicitan dinero y lo guardan de tal forma que pueden disponer de él ante cualquier eventualidad. ${ }^{10}$ Para los hogares ecuatorianos, el dinero es reserva de valor, no solamente se utiliza para «comprar bienes más fácilmente» (Romer, 2012, pp. 239-240).

Keynes en la TGEID utiliza la expresión hoarded money para representar al dinero que estaba durmiendo en la economía, al dinero que representa «reserva de valor». Entonces, ¿por qué guardar el «dinero que duerme» en la economía?, ¿será que todos los hogares ecuatorianos están locos? Keynes respondería que no, los hogares ecuatorianos, y los hogares que guardan dinero como reserva de valor, tienen miedo al fututo, lo cual se resume en «la demanda de dinero es una medida de nuestra inquietud», «un barómetro de nuestro grado de desconfianza hacia nuestros propios cálculos y convenciones respecto al futuro» (Keynes, 1936, pp. 115-116). Keynes parece haber entendido muy bien la economía ecuatoriana hace muchos años atrás; los ecuatorianos están inquietos y, debido a que están inquietos, guardan dinero — depósitos - y no otros activos - terrenos, casas, acciones, bonos, títulos - como reserva de valor. Los hogares ecuatorianos prefieren guardar dinero a pesar de que su rentabilidad sea negativa en lugar de comprar un terreno, por ejemplo, del cual percibirían una renta.

Entonces, ¿por qué la mejor medida de nuestra inquietud es guardar dinero? Keynes lo explica a través del importante aporte teórico de K. Marx (1867, pp. 175-176), cuando define al 
dinero como «poder general de compra». Esta poderosa expresión de Marx permite introducir otra categoría en el análisis, la incertidumbre o inquietud, que significa que cada hogar no conoce lo que va a necesitar en un período de tiempo que puede ser un año o tan solo después de unos minutos. En efecto, un terreno no es más que eso, si llegara a quemarse, el hogar ya no podría disponer de ese activo; si ese terreno sirve únicamente para producir se podría obtener la producción, o, si se lo alquilara, se percibiría una renta; una casa únicamente sirve para alquilarla a quien demande un servicio habitacional, y el hogar no conoce si la medida de su incertidumbre sería cubierta únicamente con la producción o la renta, o el alquiler. ¿Qué más podría necesitar en el futuro? El único activo con el cual los hogares podrían comprar todo lo que necesitan es el dinero porque es "poder general de compra».

Ante lo expuesto se podría argumentar que el hogar tiene la posibilidad de contratar un seguro que le permita resguardar al terrero ante una posible eventualidad. En el caso de presentarse cualquier caso fortuito o de fuerza mayor que esté expresamente contemplado en su contrato, podría recuperar ese activo, pero puede pasar un sinnúmero de eventualidades que no necesariamente pueden estar cubiertas por el seguro. En efecto, los hogares ecuatorianos y, de forma más amplia, los hogares en general, guardan el dinero como reserva de valor debido a que viven en un entorno de incertidumbre. Entonces, el hecho mismo de que los hogares guarden dinero como reserva de valor significa que la composición del portafolio de sus activos sería: dinero y otros activos. La teoría de preferencia de liquidez en la TGEID «describe los factores que influyen en las decisiones de los agentes con respecto a la composición de su riqueza» (Bertocco, 2006, p. 9); es decir, aporta en la explicación de cuál sería la fracción de los activos que se encuentran en dinero y cuál en otros activos. De tal forma que poner el acento en la preferencia por la liquidez «implica ver a la moneda como un stock que se debe asignar, se trata de una pieza necesaria para toda teoría monetaria» (Deleplace y Nell, 1996, p. 33).

[La moneda] es una reserva de valor [...] Pero en un mundo de la economía clásica, qué uso insensato es atribuírselo dado que reconocemos que la moneda como reserva de valor tiene características de ser estéril; mientras que en la práctica todas las otras formas de conservación de la riqueza otorgan un interés o un beneficio. ¿En virtud de qué, alguien —salvo en un asilo de locos- podría querer utilizar la moneda como reserva de valor? Por motivos en parte racionales o instintivos, nuestro deseo de tenencia de moneda como reserva de valor es un barómetro de nuestro grado de desconfianza hacia nuestros propios cálculos y convenciones respecto al futuro [...] La posesión de moneda calma nuestra inquietud, y la prima que requerimos para incitarnos a separarnos de la moneda es la medida del grado de nuestra inquietud. (Keynes, 1936, pp. 155-116)

Para afirmar que en cada momento del tiempo hay dinero que duerme - hoarded money (Keynes, 1936) - , necesitamos no solo considerar la teoría de la preferencia por liquidez, sino también la teoría del dinero endógeno. Si el problema del hogar únicamente radicara en decidir qué proporción de su remuneración la destina al consumo y cuál al ahorro y, en cuanto al ahorro, qué proporción distribuye en dinero y cuánto en otros activos, solamente se enfrentaría a un problema de preferencia por liquidez; sin embargo, sin una teoría de dinero endógeno, esta preferencia por liquidez no podría aplicarse. Al analizar este problema de elección 
del hogar desde el punto de vista de la NSN, la teoría de fondos prestables de Wicksell nos dice que los bancos comerciales son meros intermediarios financieros; es decir, reciben la proporción de ahorro de los hogares que decidieron mantener en dinero - depósitos-y lo prestan a las firmas que demanden crédito. Para el hogar, el dinero depositado que es reserva de valor, es tomado por el banco comercial y transferido a las firmas mediante un crédito cuyo destino es financiar su gasto de inversión, macroeconómicamente no podría haber dinero que duerme en la economía, por lo cual, para poder afirmar que macroeconómicamente hay dinero que duerme, desde la visión poskeynesiana, necesitamos no solo de la teoría de la preferencia por liquidez, sino también de la teoría del dinero endógeno.

Si bien la creación de dinero endógeno es un canal de financiamiento de las inversiones, no es el canal de financiamiento de las inversiones que analizó Keynes. ¿Cómo financian las firmas las inversiones en la TGEID? ${ }^{11}$ Se ilustrará la respuesta a través de un modelo stock-flow consistent $t^{12}$ simplificado, que tiene como sectores institucionales: hogares, firmas y bancos comerciales. Si un empresario emite un bono, no necesita acudir al banco comercial para que se cree nuevo dinero y se genere un depósito a su favor que después podrá gastar. Existe dinero que duerme en la economía, no es necesario crear nuevo, es preciso reactivarlo. El empresario emite un bono; con ese bono decide acudir directamente al hogar y persuadirlo para que cambie su preferencia por liquidez; si el hogar compra el bono, recompondrá su portafolio de activos y éste tendrá una mayor proporción de otros activos - bonos- que de dinero — depósitos-: el hogar redujo su preferencia por liquidez. Con este dinero, la firma puede financiar sus inversiones, gastar en sueldos y en la compra de maquinaria, pagando así a otros hogares. Se puede despertar al dinero que está durmiendo porque ya existía como reserva de valor (ver Tabla 4).

$\mathrm{Si}$ analizamos el comportamiento del hogar, en la matriz de transacciones, los ingresos disponibles son: intereses percibidos por préstamos $(i L L)$, los salarios $(w N)$, el valor el bono $(B)$ y los gastos realizados es el consumo $(p C)$. Ese diferencial entre los ingresos disponibles y los gastos realizados es el ahorro de los hogares. El hogar debe decidir cómo distribuir ese ahorro, por lo que decide distribuir una proporción en dinero a nuevos depósitos $(\Delta M)$ y, otra parte, la destina a la compra de nuevos bonos que emiten las firmas $(p B \Delta B)$. En cuanto a los bancos comerciales, estos crean nuevos créditos solicitados por las firmas $(\Delta L)$. ¿Cómo distinguir que existe una nueva modalidad de financiamiento de las inversiones? Para responder esto, analicemos la columna de cuenta capital de las firmas en la matriz de transacciones. En una primera mirada, podríamos estar tentados a concluir que las inversiones de las firmas se financian de la siguiente forma: $p I t=p B t \Delta B t+\pi t+\Delta L t(1)$. Donde $(p B t \Delta B t+\pi t)$ sería el ahorro en el tiempo $(t)$ y $(\Delta L t)$ los nuevos préstamos. Dado que el dinero es endógeno, la creación monetaria de dinero por parte de los bancos comerciales se convierte en un depósito monetario, por tanto: $\Delta L t=\Delta M t$.

La ecuación (1) puede ser reescrita como $p I t=p B t \Delta B t+\Delta M t+\pi t(2)$, donde $(p B t \Delta B t+$ $\Delta M t)$ es el ahorro de los hogares en el periodo $(t)$; $(\pi t)$ el ahorro de las firmas corporative savings en el periodo $(t)$ que podría financiar las inversiones de las firmas $(p I t=p K)$ en el periodo $(t)$. Entonces se podría decir, a primera vista, que el ahorro de la economía - ahorro de los hogares y de las empresas- financia las inversiones de las firmas. Ése sería un grave error desde el punto de vista keynesiano (ver Tabla 5). 
Las matrices de balance y transacciones son documentos de contabilidad ${ }^{14}$ que requieren una correcta interpretación. Por lo cual, si se analiza las transacciones de contabilidad expresadas en la ecuación (2), se tendría la tentación de afirmar que el ahorro de los hogares y de las firmas en el periodo $(t)$ financia las inversiones en el periodo $(t)$, corroborando así la ley de Say y la causalidad macroeconómica que indica que el ahorro $(S)$ genera inversión $(I) \Rightarrow(S \rightarrow I)$. Entonces, ¿cuál sería la correcta forma de interpretación de la columna de cuenta capital de las firmas de la matriz de transacciones? La ecuación (2) es una identidad ex post que resulta de incorporar en el análisis el multiplicador keynesiano. Consideremos: unas firmas requieren realizar sus inversiones y cuentan con dos modalidades para financiar éstas; «en una economía de crédito monetario, la financiación externa para la inversión de las empresas puede ser suministrada tanto por los hogares que poseen riqueza financiera o por el sector bancario» (Hein, 2010, p. 3); es decir, por el canal de preferencia por liquidez o por la creación endógena de dinero.

Para objetivos de esta sección se analiza el primer caso. La secuencia lógica y temporal para entender cómo las firmas financian su inversión con un cambio de preferencia por liquidez de los hogares, es la siguiente: la empresa «X» emite bonos y los hogares compran dichos bonos debido a que disponen de dinero en forma de depósitos en los bancos comerciales. Por lo cual, la transacción sería $-\Delta M=\Delta B$. Los hogares retiran parte del dinero de sus depósitos $(\Delta M)$ y compran bonos $(\Delta B)$, con lo cual se recompone el portafolio de activos de los hogares. Ahora dispondrán de más bonos y menos depósitos — menos liquidez-. Es decir, ha cambiado la riqueza de los hogares debido a su cambio en la preferencia por liquidez.

Con el dinero que la empresa «X» recibió por los bonos que vendió a los hogares, compra el bien capital $(p K)$, realiza la inversión. La empresa «Y» que le vendió el bien capital antes señalado, dispone ahora de dinero en el valor correspondiente al valor de los depósitos que los hogares retiraron del banco comercial para comprar los bonos a la empresa «X». Con ese valor, la empresa «Y» paga ingresos a otros hogares. Entonces, aumentan los depósitos de esos hogares en los bancos comerciales $(\Delta M)$. Por el momento, la variación total de depósitos en esta economía es cero $\Delta M=-\Delta M+\Delta M=0$, y la variación de los bonos $(\Delta B)$ es igual a la variación de la inversión que es positiva $(\Delta B=I>0)$. Es decir, si $\Delta M+\Delta B=I>0$, significa que la riqueza de los hogares $(W)$ comprendida con depósitos y bonos ha incrementado en el mismo valor que el bien capital $(p K)$. En este momento comienza a actuar el multiplicador keynesiano. Los otros hogares que recibieron ingresos por los depósitos de aquellos hogares que compraron los bonos emitidos por la empresa «X», comienzan a consumir. El hogar se enfrenta a la decisión de qué proporción asignar al consumo y qué proporción al ahorro. En este punto, empieza el ahorro. Únicamente porque la inversión ya se ha producido se genera el ahorro. El ahorro es una consecuencia de la inversión, se evidencia la causalidad macroeconómica que Keynes explicó en la TGEID: la inversión $(I)$ genera el ahorro $(S) \Rightarrow(I \rightarrow S)$.

Entonces, la identididad ex post —ecuación (2) - significa que la inversión financiada por la decisión de los hogares de comprar bonos, genera ahorro en un monto igual a la inversión. Así, la columna de cuenta capital de las firmas no significa que el ahorro financia las inversiones, corrobora que la inversión genera posteriormente un monto de ahorro idéntico al monto de la inversión. Es una identidad ex post en ese sentido. En esta modalidad de financiamiento 
Tabla 4. Matriz de balance

\begin{tabular}{lll}
\hline CARACTERÍstiCAS & ESCUELA POST-KEYNESIANA & MAINSTREAM \\
\hline Tasa de interés & $\begin{array}{l}\text { Variable de distribución que en cierta } \\
\text { medida puede ser controlada por la }\end{array}$ & Surge de las condiciones de mercado \\
& autoridad monetaria. & \\
\hline Tasa referencial & Es establecida por el banco central, es & Es influenciada por las condiciones de \\
& exógena & mercado \\
\hline Preferencias por liquidez & $\begin{array}{l}\text { Determina las diferencias respecto de } \\
\text { la tasa referencial }\end{array}$ & Determina la tasa de interés \\
\hline La tasa natural & Toma múltiples valores o no puede & $\begin{array}{l}\text { Es única basada en el ahorro y } \\
\text { productividad }\end{array}$ \\
\hline
\end{tabular}

Nota: Representación de la preferencia por liquidez de los hogares a través de un modelo stock-flow consistent simplificado.

Tabla 5. Matriz de transacciones para el periodo $t$

\begin{tabular}{lll}
\hline CARACTERÍSTICAS & ESCUELA POST-KEYNESIANA & MAINSTREAM \\
\hline Distinción de Schumpeter & Análisis intrínsecamente monetario & Análisis intrínsecamente real \\
\hline Perturbaciones Financieras & Tiene efectos en el corto y largo plazo & Tiene efectos solo en el corto plazo \\
\hline Causalidad de la inflación & El crecimiento de los agregados mo- & $\begin{array}{l}\text { La inflación de los precios es causada por } \\
\text { el exceso de la oferta monetaria }\end{array}$ \\
& netarios es causado principalmente & \\
& por el crecimiento de la producción y & \\
& los precios & Ahorro determina Inversión \\
\hline Causalidad macro & Inversión determina el Ahorro &
\end{tabular}

de las inversiones de las firmas, los hogares utilizan la riqueza que ya disponen para modificar su preferencia por liquidez y financiar la inversión, en tanto que en la modalidad de creación endógena de dinero, se crea dinero que no se dispone para financiar la inversión. Son dos formas distintas de financiamiento de la inversión que son coincidentes, en las que originariamente se invierte y posteriormente se crea el ahorro. Por lo cual, la sumatoria de las transacciones de la columna de cuenta capital de las firmas es cero.

Los poskeynesianos han dado mucha importancia analítica a la creación endógena de dinero, que es una de las modalidades de financiamiento que sin lugar a duda es fundamental; sin embargo, no es la única modalidad. Otra modalidad posible es reactivar al dinero que estaba durmiendo en la economía - hoarded money - como reserva de valor. Esta importante intuición de Keynes - la preferencia por liquidez — ha sido relegada por los poskeynesianos influenciados exclusivamente por Kaldor (1982). ${ }^{15}$ Es por eso que Lovoie (2014), en su libro PostKeynesian Economics: New foundations, analiza la «reincorporación de las preferencias por liquidez» del público, que era el corazón de la TGEID. Así, en una economía poskeynesiana, las firmas podrían decidir financiar sus inversiones acudiendo al banco o directamente a los hogares (Hein, 2010, p. 3). Sin embargo, el modelo macroeconómico de Fontana y Setterfield (2006 
y 2009) analiza exclusivamente la posibilidad de que las inversiones sean financiadas con la creación endógena de dinero y relega completamente la preferencia por liquidez. Actualmente, se presenta un debate sobre la reincorporación de la preferencia por liquidez en el análisis; paradójicamente, los poskeynesianos parecen haber olvidado este elemento puramente keynesiano. El debate busca responder cómo, en qué medida, a través de qué canales, la preferencia por liquidez afecta a la tasa de interés que deciden los bancos comerciales. «El banco central determina el precio de su dinero, la tasa de interés base, y los bancos comerciales determinan un mark-up sobre la tasa de interés base cuando financian crédito a los inversionistas» (Hein, 2010, p. 3). De este análisis existe muy poca reflexión teórica, más aún para países que no cuentan con moneda propia, como es el caso de Ecuador.

En este marco analítico, los hogares, así como los bancos comerciales, podrían financiar las inversiones de las firmas. Hay dos agentes que compiten para convertirse en su fuente de financiamiento. Si los hogares llegaran a financiar a las firmas mediante la compra de bonos que éstas emiten, los bancos dejarían de percibir los beneficios por los intereses de los créditos no realizados. Cuando el mercado de bonos es grande y las firmas se financian vía preferencia por la liquidez, los bancos comerciales pierden ganancias, entonces reaccionan. ¿Cómo reaccionan? Probablemente bajando el mark-up sobre la tasa decidida por el banco central. Se podría interpretar que el mark-up no es exógeno como se presenta en muchos modelos poskeynesianos, es el resultado de la competencia entre los hogares y los bancos comerciales por financiar las inversiones, es un parámetro endógeno.

La reincorporación de la preferencia por liquidez de los hogares afecta la política de los bancos comerciales, porque los bancos estarían perdiendo oportunidades de ganancia. Es decir, si la tasa que determina el banco comercial es un mark-up sobre la tasa base del banco central $i L=(1+\tau) i B C$, donde $i L$ es la tasa de interés que determinan los bancos comerciales, $\tau$ es el mark-up y $i B C$ es la tasa de interés base determinada por el banco central; entonces, $\tau$ es endógena y podría ser considerado un parámetro de reacción de los bancos comerciales cuando incrementa el número de bonos en la economía debido a que se despierta el dinero que duerme en la economía. Se reincorpora, así, una categoría analítica puramente keynesiana en el marco teórico poskeynesiano. Complementariamente, desde la visión «horizontalista» los bancos comerciales establecen el mark-up sobre la tasa de interés que deben pagar al banco central cuando éstos realizan a su favor avances. El banco central determina la tasa de interés. ${ }^{16}$ Pero, ¿cuál tasa de interés? La incorporación de la teoría de la preferencia por liquidez permitirá entender cómo la determinación de una tasa de interés por parte de la autoridad monetaria afecta a la estructura de las demás tasas de interés. ${ }^{17}$ Keynes (1936) dice que la preferencia de liquidez determina la tasa de interés, «pero aún no está aún muy claro si se refiere a la tasa de corto plazo, la tasa de largo plazo o el diferencial entre las tasas de corto y largo plazo» (Lavoie, 2014, p. 231).

\section{CONCLUSIÓN}

El debate actual sobre la naturaleza del dinero es fundamental para responder la pregunta cuáles son los vínculos monetarios y fiscales existentes con las políticas de estabilización, ya que 
de sus conclusiones depende el establecimiento de los objetivos de la política económica y sus efectos previsibles. El debate sobre la exogeneidad y endogeneidad del dinero plantea un punto crucial en el análisis de la política monetaria y fiscal en un país dolarizado como es el caso de Ecuador. Si el dinero es exógeno, la pérdida de soberanía monetaria debido a la dolarización coincide con la pérdida de política monetaria; si al contrario, el dinero es endógeno, la pérdida de soberanía monetaria coincide con la pérdida parcial de la política fiscal como un instrumento activo para implementar políticas de estabilización. El debate teórico sobre la naturaleza del dinero presenta una convergencia en la aceptación de la naturaleza endógena del dinero. Se presentan dos tipos de endogeneidad: i) la neokeynesiana o de la NSN, y ii) la poskeynesiana, con importantes diferencias en el marco teórico que rige la acción de los bancos centrales, la determinación de las herramientas de política monetaria y las funciones de dinero.

El análisis propuesto en este documento da cuenta de que el paradigma que más ha reflexionado sobre una economía intrínsecamente monetaria es el poskeynesiano. Keynes (1933, p. 85) evidencia que «las fluctuaciones de la demanda efectiva pueden describirse adecuadamente como un fenómeno monetario». Además, indica que es ilusorio intentar analizar el funcionamiento efectivo de nuestras economías sin recurrir, desde el inicio, a la moneda. La comprensión de los mecanismos económicos esenciales requiere de ésta desde el punto de partida de sus análisis; no se le debe introducir a posteriori para así dar cuenta de su existencia, como si ello no cambiara fundamentalmente nada en la dinámica del sistema económico. Las esferas reales y monetarias se encuentran íntimamente ligadas, dado que la moneda se vincula a la economía en la producción por medio de los bancos. No obstante, la consistencia de este paradigma aún es incompleto, se ha enfocado casi exclusivamente en considerar la creación endógena de dinero por los bancos como la única fuente posible de financiamiento de la inversión de las firmas; por ello, Bertocco (2006, p. 1) afirma que «la teoría endógena del dinero constituye el elemento central de la teoría monetaria poskeynesiana». La reincorporación de la preferencia por liquidez como una de las fuentes de financiamiento de la firma, puede contribuir a identificar cuáles son los canales con los que se puede afectar a la demanda agregada y el ciclo económico, más aún en países que no cuentan con moneda propia.

Para entender la dolarización en un marco teórico poskeynesiano, es necesario superar las limitaciones expuestas en este documento respecto del modelo macroeconómico de dinero endógeno desarrollado por Fontana y Setterfield (2006 y 2009), que sin lugar a duda ha sido una herramienta muy útil para explicar, por ejemplo, el credit crash del 2007: ¿Por qué no funcionó la política monetaria, pero sí la política fiscal para estabilizar el ciclo económico de los Estados Unidos en el American Recovery and Reinvestment Act of 2009? Por tanto, es necesario que este modelo sea complementado con la teoría de la preferencia por liquidez; y, además, se modele para una economía abierta, dado que otro limitante del esquema monetario de dolarización es la balanza de pagos. Estas son las extensiones cruciales que se evidencian necesarias para entender los vínculos monetarios con las políticas de estabilización.

Cuando un país atraviesa la fase de contracción del ciclo económico, los agentes económicos muestran diferentes comportamientos, como los hemos evidenciado en el análisis de la economía ecuatoriana durante el período del primer trimestre 2014 al segundo trimestre de 2016. Los hogares tienen una mayor propensión a ahorrar, las firmas a invertir menos, los 
bancos a aumentar su preferencia por liquidez y el gobierno - si adopta una posición keynesiana - aplicará políticas contracíclicas que tienen como objetivo aumentar su gasto para incentivar la demanda agregada y, de esta forma, suavizar los efectos negativos de la reducción del PIB que pueden ser resultado de shocks internos y/o externos. En este contexto, los hacedores de política económica indican que están «atados de manos» debido a que están imposibilitados de aplicar políticas contracíclicas que incentiven y reduzcan los efectos negativos sobre la demanda agregada, por lo cual aplican políticas procíclicas. Sin embargo, como se deriva del análisis, un país que no cuenta con moneda propia puede implementar la política monetaria. Si adicionalmente se enfrenta a un entorno macroeconómico de incertidumbre, se evidencia que se acentúa la preferencia por liquidez del público, es decir, la necesidad de la tenencia de moneda como reserva de valor (Keynes, 1936, pp. 115-116), por lo que podría ocurrir que esta preferencia por liquidez se modifique cuando se modifica el ciclo económico. La preferencia por liquidez requiere de un particular análisis para un país pequeño, dolarizado y abierto como Ecuador. En el análisis general de la preferencia por liquidez, un hogar toma la decisión de estructurar su portafolio de activos, asignando una parte de sus ahorros a depósitos en los bancos comerciales y, otra, a la compra de bonos y otros activos reales. Un hogar ecuatoriano se enfrenta a un problema aún más complejo, debe asignar su ahorro además de a los depósitos y otros activos reales, a efectivo. Keynes (1936, p. 167) decía que «el dinero coexiste con los depósitos bancarios».

Probablemente, el parámetro de preferencia por efectivo sea endógeno, lo cual implicaría que cuando la economía tiene un desempeño favorable y se encuentra en una etapa de expansión del ciclo económico, esta preferencia por efectivo se reduzca. Recordemos que cuando el precio del petróleo superaba los USD 100 por barril, los ecuatorianos no preferían guardar efectivo. No obstante, cuando el precio del petróleo disminuyó vertiginosamente y han confluido otros shocks exógenos - como la apreciación del dólar- empiezan las malas noticias respecto al desempeño económico; entonces cambia la preferencia por efectivo de los hogares ecuatorianos, guardan efectivo como una medida de su inquietud. Así, cuando nos encontramos en la etapa de recesión del ciclo económico, aumenta la preferencia por efectivo. De lo cual se desprende que la preferencia por efectivo de los hogares no es exógena, podría ser endógena.

Parguez y Seccareccia (2000) y Rochon (1999), teóricos del circuito monetario, consideran que la preferencia por liquidez conduce a la interrupción del flujo de renta hacia las empresas y a una demanda global insuficiente. Si parte del ingreso creado se conserva en forma de fondos líquidos, los empresarios no podrán recuperar mediante las ventas la totalidad de los montos invertidos en la producción. Siguiendo el principio de la demanda efectiva, esto deprime las previsiones de beneficios de los empresarios, penaliza el desarrollo de la producción y, por ende, la mejora en la demanda laboral. Keynes (1936, p. 411), en su presentación de los principales lineamientos de su teoría monetaria de la producción, afirma que «las depresiones son fenómenos específicos de la economía en la cual [...] la moneda no es neutral». Así, la aplicación de las políticas contracíclicas solo será posible si el gobierno cuenta con dos herramientas activas fundamentales: la política monetaria y política fiscal para incentivar la demanda agregada; por lo cual la capacidad de un país para controlar la política monetaria y las tasas de interés está ligada a la soberanía nacional. Un país capaz de controlar esta política es un país que 
puede influir en el curso de su economía, aspecto esencial para la gestión de la política económica nacional. Renunciar a la política monetaria es esencialmente atarse las manos y aceptar las decisiones de la Reserva Federal (FED), que establece esta política de acuerdo con el ciclo económico de Estados Unidos y sus expectativas inflacionarias. Por otra parte, aún la política fiscal puede ser en sí misma limitada por las expectativas monetarias, creando así nuevos obstáculos para que una economía dolarizada se conduzca con una política macroeconómica independiente y capaz de enfrentar los shocks externos e internos propios de su estructura económica. (Rochon y Seccareccia, 2003, p. 16).

La política monetaria tiene un papel central, dado que al mantener tasas de interés bajas, el banco central puede sostener la demanda global y la solvencia de los prestatarios. La política fiscal es de igual modo determinante, ya que puede alimentar la demanda y evitar la degradación de la solvencia de los prestatarios. Dicha solución puede tener un impacto en la distribución del ingreso con el objetivo de estimular el consumo. El gasto público constituye una salida para las empresas que venden directamente al Estado o que se benefician de los ingresos transferibles. Las políticas coyunturales deben hacer lo necesario para sostener el otorgamiento de créditos y, más aún, la actividad económica en su totalidad (Piégay y Rochon, 2005, pp. 10-11)

Una economía dolarizada presenta reducidas opciones para enfrentar shocks exógenos dado que restringe a la política monetaria como herramienta activa. Izurieta (2003, pp. 159-160) indica que la política económica, por un lado, podría orientarse a mantener las prioridades previamente determinadas y que han sido estructuradas en respuesta a los patrones de demanda, empleo, ingreso y distribución; mientras que deja al mercado la tarea de consolidación financiera. Otra opción sería amortiguar el shock ajustando la posición fiscal mediante la reducción del gasto público, logrando así - por contracción - la consolidación financiera, sin tomar en cuenta que el patrón estructural de la demanda podría ser alterado, tal vez de forma irreversiblemente. Como corolario, la política fiscal por sí sola no es capaz de ayudar a una economía a recuperarse después de un shock externo y garantizar, al mismo tiempo, la estabilidad financiera. La experiencia parece sugerir que los países que aplican política monetaria restrictiva $^{18}$ y se encuentran en acuerdos monetarios — como la dolarización-, son más propensos a sufrir de desempleo crónico o debilidad financiera como consecuencia de los shocks exógenos (Izurieta, 2003, p. 143). Finalmente, como se evidencia, existen vínculos monetarios y fiscales con las políticas de estabilización que requieren ser analizados con mayor profundidad en una economía dolarizada.

\section{NOTAS}

1 De acuerdo con el Banco Central del Ecuador, el índice de los términos de intercambio se define como el precio relativo de lo exportable en relación con lo importable. Estadísticamente se calcula como el cambio en la proporción de un índice de precios de exportaciones en relación a un índice de precios de importaciones, relativos a un año base. Si los precios de las exportaciones de un país aumentan o se reducen respecto a los de las importaciones, se dice que las relaciones de intercambio de mercancías mejoran y, viceversa. Véase https://contenido.bce.fin.ec/documentos/PublicacionesNotas/Catalogo/ Cuadernos/ Cuad11o.pdf

2 Se adopta así el enfoque keynesiano de las políticas de estabilización. 
3 La economía monetaria investiga la relación entre las variables económicas reales a nivel agregado - como el producto real, la tasa de interés real, el empleo y el tipo de cambio real- y las variables nominales - como la tasa de inflación, la tasa de interés nominal, el tipo de cambio nominal y la oferta monetaria- (Walsh, 2010, p. 18).

4 Moore (1988, p. 487) argumentó que «el banco central reacciona con las tasas de interés a corto plazo como la variable dependiente», que dependería «del estado futuro de la economía doméstica (factores de demanda)», así como de los objetivos de las autoridades monetarias, incluyendo el «pleno empleo, estabilidad de precios, crecimiento, balanza de pagos, términos de intercambio, tasas de cambio, distribución del ingreso» (Moore, 1989, p. 264).

5 Piégay y Rochon (2005) indican que es necesario destacar que la lucha contra la inflación beneficia prioritariamente a los acreedores.

6 De acuerdo con la ley de Say, el gasto por absorber la producción industrial — demanda global — es igual a la suma de los costes de la producción global —oferta global— incluidos los beneficios brutos. En una economía regida por la ley de Say, los costos de producción son siempre recuperados íntegramente a través de la venta de la producción. La demanda global nunca es insuficiente, las curvas de demanda y oferta agregadas coinciden y no existe ningún obstáculo para el pleno empleo. (Davidson, 2003, pp. 2930). Por esto, tanto Friedman como Tobin postulan que el dinero no afecta el flujo de producción real, por lo menos a largo plazo, planteando así el axioma de neutralidad del dinero. Este axioma significa, según Hahn (1983), que las «acciones y planes de los agentes están determinados por objetivos que no dependen de ninguna magnitud nominal. No se preocupan más que de las cosas "reales" como los bienes, [...] el ocio y el esfuerzo» (p. 44). Keynes (1936) llamó a este tipo de economía una "economía no monetaria».

7 Moore (1998) afirma que la creación monetaria está determinada por la demanda y, a su vez, guiada por los créditos. Los bancos comerciales solamente pueden prestar a quienes lo demandan, por lo cual su oferta de préstamos está determinada por la demanda (Piégay y Rochon, 2005, p. 42).

8 La crisis financiera inició en noviembre en 1998 y llegó a su momento crítico a finales del 200o, donde las autoridades de ese entonces decidieron decretar el esquema monetario de dolarización. Eso implicó el abandono de la moneda nacional y la adopción del dólar de los Estados Unidos de Norteamérica como moneda de curso legal.

9 Para este análisis, en la acepción de bancos se representa a todas las entidades financieras que conforman el sistema financiero nacional.

10 Los poskeynesianos han asociado el concepto de preferencia de liquidez a un entorno de fundamental incertidumbre. En este entorno, los agentes económicos no conocen la probabilidad de distribuciones, son conscientes de que las secuencias pasadas de sucesos pueden no volver a ocurrir, esperan aprender más en un futuro próximo y, por lo tanto, pueden retrasar las decisiones. Este tipo de preferencia de liquidez está inversamente relacionado con el grado de confianza y la fiabilidad de las creencias. (Lavoie, 2014, p. 238). 11 En la TGEID, Keynes pasa por alto completamente el proceso de creación de dinero llevado a cabo por los bancos para financiar las decisiones de inversión de las empresas. (Bertocco, 2006, p. 8).

12 Los modelos stock-flow consistent son herramientas de modelación macroeconómica que se construyen en base a tres elementos (Dos Santos, 2002): i) una matriz de stocks en la que se encuentran los balances - activos y pasivos- de los sectores institucionales considerados en la modelación, ii) una matriz de flujos en la que se determinan los orígenes y destinos de todas las transacciones que se efectúan en una economía, de manera que no existan «agujeros negros» (Godley, 1996), es decir, cada flujo viene de algún lado y va a algún lado; y iii) un conjunto de ecuaciones que determinan las reglas de actualización de los stocks y la dinámica de las variables consideradas. Estos modelos tienen la potencialidad de explicar de forma clara la interacción entre la parte real y la financiera de la economía que está siendo modelada, permitiendo así «rastrear» con precisión las relaciones entre los distintos sectores.

13 Los bonos de largo plazo se definen como títulos de la deuda pública consolidada — consols -, también llamados perpetuidades porque nunca son redimidos. Se supone que cada consol es un pedazo de papel que paga al propietario un dólar después de un período transcurrido, este pago de un dólar es el cupón de la perpetuidad. Si hay $B$ papeles en existencia al final del período anterior, se deduce que el 
flujo total de los pagos por intereses sobre estos activos en el período actual es simplemente $B$, ya que cada pedazo de papel proporciona ingresos por intereses de un dólar. (Godley, W y M. Lavoie, 2007, p. 131).

14 Godley y Cripps (1983, p. 13) afirman que «el hecho que los stocks y flujos monetarios deben satisfacer las identidades contables en los presupuestos individuales y en una economía es un todo, proporciona una ley fundamental de la macroeconomía».

15 Kaldor (1982, p. 21) indica que «es preciso abandonar la teoría de preferencia por liquidez».

16 En cuanto a la función de reacción del banco central, Rochon y Setterfield (2008), indican que a nivel más global los bancos centrales pueden seguir una política contracíclica o un enfoque de distribución de ingresos. Una política contracíclica significa que el banco central intenta ajustar un cierto agregado económico cambiando la tasa de interés nominal objetivo, posiblemente cambiando también la tasa de interés real. En el caso del enfoque de distribución de ingresos, el banco central establece la tasa de interés nominal o real sin intentar ajustar las condiciones macroeconómicas. La política contracíclica corresponde al comportamiento actual de los bancos centrales (Lavoie, 2014, p. 234).

17 La FED, el Banco Central Europeo, y el Banco de Inglaterra - por mencionar algunos de los bancos más grandes del mundo- se reúnen mensualmente para determinar la tasa de interés de corto plazo usada por los bancos comerciales y otras instituciones financieras, y además, también, para determinar todas las otras tasas de interés en la economía. (Fontana y Setterfield, 2009, pp. 144-145)

18 Implica que el banco central está tratando de reducir la demanda de dinero y limitar el ritmo de expansión de la economía.

\section{REFERENCIAS}

Bertocco, G. (febrero, 2006). Some observations about the endogenous money theory. Cuaderno de trabajo, Università degli Studi dell'Insubria, Varese, Italia.

Davidson, P. (2003). ¿Cuáles son los elementos esenciales de la Teoría Monetaria Post-Keynesiana? En P. Piégay y P. Rochon, Théories Monétaires Post Keynésiennes (pp. 29-30). París, Francia: Ediciones Económicas.

Dos Santos, C. H. (2002). Notes on the stock-flow consistent approach to macroeconomic modeling. Three Essays in Stock-Flow Consistent Macroeconomic Modeling. Recuperado de http:// www.ipc-undp.org/publications/srp/Notes\%20on\% 20the\%2oStock-Flow\%2oConsistent\%2O Approach\%2oto\%2oMacroeconomic\%2oModeling.pdf

Deleplace, G. y Nell, E. (1996). Introduction: Monetary Circulation y Effective Demand. In G. Deleplace and E. J. Nell (Eds.), Money in Motion. The Post Keynesian y Circulation Approaches, (pp. 3-41). London, UK: Macmillan.

Dullien, S. (2011). The New Consensus from a traditional Keynesian and post-Keynesian perspective: a wothwile foundation for research or just a waste of time? Économie Allpiguée, (64), 173-200.

Fontana, G. and Setterfield, M. (2009). Macroeconomic Theory and Macroeconomic Pedagogy. Hampshire, UK: Palgrave Macmillan.

Galí, J. (2008). Monetary policy, inflation and business cycle. An introduction to the New Keynesian Framework. Princeton, usa: Princeton University Press.

Godley, W. (1996). Money, finance and national income determination: an integrated approach. Working Paper, (167), (s. p).

Godley, W. and Cripps, F. (1983). Macroeconomics. London, UK: Fontana.

Godley, W. and Lavoie, M. (2007). Monetary Economics: An integrated approach to credit, money, income, production and wealth. Hampshire, uk: Palgrave Macmillan. 
Hein, E. (2010). The rate of interest as a macroeconomic distribution parameter: Horizontalism and PostKeynesian models of distribution of growth. (s. d.): Institute for International Political Economy Berlin.

Izurieta, A. (2003). Dollarization as a tight rein on the fiscal stance. In L. P. Rochon and M. Seccareccia, Dollarization: Lessons from Europe and the Americas, (pp. 143-164). London, uk: Routledge.

Kaldor, N. (1982). The Scourge of Monetarism. Oxford, uk: Oxford University Press.

Keynes, J. M. (1933). The distinction between a co-operative economy and an entrepreneur Economy. In J. M. Keynes, The Collected Writings, vol. xxix, (pp. 76-106). London, uk: Macmillan Press.

Keynes, J. M. (1936). The General Theory of employment, interest and money. London, Uк: Palgrave MacMillan.

Lavoie, M. (2014). Post-Keynesian Economics: New Foundations. Cheltenham, UK-Northampton, UsA: Edward Elgar.

Marx, K. ([1867] 1996). El Capital. Crítica de la economía política, tomo I. México DF, México. Siglo xxi.

Moore, B. J. (1988). Horizontalist and Verticalists. The Macroeconomics of credit money. Cambridge, UK: Cambridge University Press.

Parguez, A. and Seccareccia, M. (2000). The Credit Theory of Money: The Monetary Circuit Approach. In J. Smithin (Ed.), What is Money?, (pp. 101-123). Londres, UK: Routledge.

Piégay, P y Rochon L. P. (2005). Teorías monetarias post-keynesianas: Una aproximación de la escuela francesa. Revista Latinoamericana de Economía «Desarrollo», 36(143), (s. p.).

Rochon, L. (1999). Credit, money and production. An alternative Post Keynesian approach. Cheltenham, UK: Edward Elgar.

Rochon, L. and Seccareccia, M. (2003). Dollarization: Lesson from Europe and the Americas. London, UK: Routledge.

Romer, D. (2011). Advanced Macroeconomics. New York, usA: McGraw Hill.

Sraffa, P. (1960). Production of Commodities by means of Commodities: Prelude to a Critique of Economic Theory. Cambridge, uk: Cambridge University Press.

Walsh, C. (2010). Monetary theory and policy. Cambridge-Massachussets, USA: The MIT Press.

Wicksell. K. (1898). Interest and Prices. London, UK: Royal Economic Society.

Woodford, M. (2003). Interest and Prices: Foundations of a Theory of Monetary Policy. Princeton, usA: Princeton University Press. 